\title{
The efficacy of routine use of recombinant human bone morphogenetic protein-2 in occipitocervical and atlantoaxial fusions of the pediatric spine: a minimum of 12 months' follow-up with computed tomography
}

\author{
Christina Sayama, MD, MPH, ${ }^{1,2}$ Caroline Hadley, BS, ${ }^{1,2}$ Gina N. Monaco, MD, PhD, ${ }^{3}$ Anish Sen, MD, ${ }^{1,2}$ \\ Alison Brayton, RN, ${ }^{1,2}$ Valentina Briceño, RN, ${ }^{1,2}$ Brandon H. Tran, MD, ${ }^{4}$ Sheila L. Ryan, JD, MPH, ${ }^{1,2}$ \\ Thomas G. Luerssen, MD, ${ }^{1,2}$ Daniel Fulkerson, MD, ${ }^{3}$ and Andrew Jea, MD ${ }^{1,2}$

\begin{abstract}
1Neuro-Spine Program, Division of Pediatric Neurosurgery, and `Department of Pediatric Radiology, Texas Children's Hospital; 2Department of Neurosurgery, Baylor College of Medicine, Houston, Texas; and ${ }^{3}$ Division of Pediatric Neurosurgery, Riley Children's Hospital, Department of Neurosurgery, Indiana University, Indianapolis, Indiana
\end{abstract}

\begin{abstract}
OBJECT The purpose of this study focusing on fusion rate was to determine the efficacy of recombinant human bone morphogenetic protein-2 (rhBMP-2) use in posterior instrumented fusions of the craniocervical junction in the pediatric population. The authors previously reported the short-term (mean follow-up 11 months) safety and efficacy of rhBMP-2 use in the pediatric age group. The present study reports on their long-term results (minimum of 12 months' follow-up) and focuses on efficacy.

METHODS The authors performed a retrospective review of 83 consecutive pediatric patients who had undergone posterior occipitocervical or atlantoaxial spine fusion at Texas Children's Hospital or Riley Children's Hospital during the period from October 2007 to October 2012. Forty-nine patients were excluded from further analysis because of death, loss to follow-up, or lack of CT evaluation of fusion at 12 or more months after surgery. Fusion was determined by postoperative CT scan at a minimum of 12 months after surgery. The fusion was graded and classified by a board-certified fellowship-trained pediatric neuroradiologist. Other factors, such as patient age, diagnosis, number of vertebral levels fused, use of allograft or autograft, dosage of bone morphogenetic protein (BMP), and use of postoperative orthosis, were recorded.
\end{abstract}

RESULTS Thirty-four patients had a CT scan at least 12 months after surgery. The average age of the patients at surgery was 8 years, 1 month (range 10 months-17 years). The mean follow-up was 27.7 months (range 12-81 months). There were 37 fusion procedures in 34 patients. Solid fusion (CT Grade 4 or $4-$ ) was achieved in $89.2 \%$ of attempts (33 of 37 ), while incomplete fusion or failure of fusion was seen in $10.8 \%$. Based on logistic regression analysis, there was no significant association between solid fusion and age, sex, BMP dose, type of graft material, use of postoperative orthosis, or number of levels fused. Three of 34 patients (8.8\%) required revision surgery.

CONCLUSIONS Despite the large number of adult studies reporting positive effects of BMP on bone fusion, our longterm outcomes using rhBMP-2 in the pediatric population suggest that rates of fusion failure are higher than observed in contemporary adult and pediatric reports of occipitocervical and atlantoaxial spine fusions.

http://thejns.org/doi/abs/10.3171/2015.2.PEDS14533

KEY WORDS bone morphogenetic protein; pediatric spine; spinal instrumentation; fusion rate

$\mathrm{T}$ HE use of autograft bone to achieve a spinal fusion is the gold standard by which all other grafting options are judged. Its dependable rate of incorporation leading to a successful spinal arthrodesis has been documented. ${ }^{8,13}$ The potential benefits of using recombi- nant human bone morphogenetic protein-2 (rhBMP-2) over autograft or allograft bone are numerous. They may include decreased operative time, blood loss, donor-site morbidity, ${ }^{4}$ transmission of infection associated with use of allograft, ${ }^{1}$ and rate of pseudarthrosis. ${ }^{5}$ In addition, the

ABBREVIATIONS BMP = bone morphogenetic protein; RCH = Riley Children's Hospital; rhBMP-2 = recombinant human BMP-2; TCH = Texas Children's Hospital. SUBMITTED October 2, 2014. ACCEPTED February 19, 2015.

INCLUDE WHEN CITING Published online April 10, 2015; DOI: 10.3171/2015.2.PEDS14533.

DISCLOSURE The authors report no conflict of interest concerning the materials or methods used in this study or the findings specified in this paper. 
unlimited quantity and immediate availability of rhBMP-2 make it useful in certain pediatric spine applications, although its cost may be prohibitive in some circumstances.

Previous studies of pediatric occipitocervical and atlantoaxial constructs had reported much higher fusion rates (around 98\% to 100\%). ${ }^{7,11,13,16}$ In recent comparisons of fusion rates following occcipitocervical and atlantoaxial instrumented fusion using a large clinical series and administrative data sets, Mazur et al..$^{15}$ and Hankinson et al., respectively, reported higher rates of fusion failure (i.e., occipitocervical failure rate: mean $19.0 \%$, range $6.25 \%-$ $25.9 \%$; atlantoaxial failure rate: mean $11.1 \%$, range $0.0 \%-$ $14.3 \%$ ) than previously reported in the literature (Hankinson TC, Anderson RCE, Brockmeyer DL, Torok M, Libby AM, Pediatric Craniocervical Society: Comparison of Fusion Rates Following Occipitocervical and Atlantoaxial Instrumented Arthrodesis Using Administrative Datasets. Paper presented at the 2013 Annual Meeting of the American Society of Pediatric Neurosurgeons, Kauai, Hawaii, USA, February 14, 2013). Moreover, there were no statistically significant differences in failure rates between the graft groups-Group 1: structural autograft; Group 2: structural allograft; Group 3: nonstructural graft; and Group 4: no graft.

The purpose of this study was to examine the longterm ( $\geq 12$ months) efficacy of rhBMP-2 use as an adjunct in terms of fusion rate after occipitocervical and atlantoaxial spine fusion procedures in pediatric patients.

\section{Methods}

This study was conducted under a protocol approved by the Baylor College of Medicine institutional review board.

We retrospectively reviewed the charts of 83 consecutive cases in which pediatric patients had undergone occipitocervical or atlantoaxial fusions with rhBMP-2 at Texas Children's Hospital (TCH) or Riley Children's Hospital (RCH) during the period from October 1, 2007, to October 30,2012. A total of 49 patients were excluded from analysis because of death (5 patients), loss to followup (8 patients), or lack of CT imaging at least 12 months after surgery (36 patients). Thirty-four patients underwent 37 procedures intended to achieve fusion. The patients' ages at surgery ranged from 10 months to 17 years, with a mean age of 8 years, 1 month. The minimum duration of follow-up was 12 months (mean 27.7 months, range 1281 months). There were 16 girls and 18 boys in the study group. Patient demographics, perioperative data, including dose of bone morphogenetic protein (BMP), and fusion outcomes were recorded (Table 1).

\section{Surgical Technique}

The senior authors (A.J. or D.F.) were the attending surgeons for all spine surgeries. The surgery consisted of routine exposure of the spine over the entire length to be instrumented. Placement of segmental instrumentation, if performed, was done in the standard fashion. Decortication of the lamina, spinous processes, and facet joints was performed using a matchstick bur after placement of spinal instrumentation.

\section{BMP Dosing}

Small (2.8 mg), medium (5.6 mg), or large $(8.0 \mathrm{mg})$ kits of rhBMP-2 were used in each case and applied on a collagen sponge (INFUSE, Medtronic Sofamor Danek). The collagen sponges were generally cut into $1-\mathrm{cm}$ strips and placed in a single layer overlying the posterior elements after thorough decortication of the bone. The amount of rhBMP-2 to be used was determined intraoperatively, depending on the surface area of the intended fusion levels.

\section{Use of Bone Graft}

The rhBMP-2 was applied as described above along with some form of bone graft. Most commonly, the rhBMP-2 was applied with demineralized bone matrix and allograft bone chips (22 of 37 procedures). In 15 of 37 procedures, allograft was used without autograft, either because local autograft was not available or because it was preferable to leave the spinous processes and interspinous ligaments intact to aid in maintaining stability. We have abandoned the practice of harvesting iliac crest (or rib) autograft due to the associated morbidities.

\section{Follow-Up}

Patients were seen in clinic at 2 weeks, 6 weeks, 3 months, 6 months, and 12 months after surgery. Patients were then followed annually. After the 12-month postoperative period, a CT scan with coronal and sagittal reconstructions was obtained to assess the deposition of bridging bone. A board-certified fellowship-trained pediatric neuroradiologist (B.H.T.) graded the quality of the bridging bone based on a modification of a previously published validated CT-based grading scale for fusion (Table 2) (Fig. 1). ${ }^{10}$ The purpose and descriptive nature of this fusion grading scale aligned with our objective of determining the quality of the fusion resulting from rhBMP-2 use. Bridwell et al. ${ }^{3}$ devised another popular scale, the Bridwell-Lenke grading system, for determining lumber posterolateral fusion; however, it was based on plain radiographs of the spine, not the gold standard CT imaging, as was used in this study.

\section{Statistical Analysis}

Categorical outcomes were compared with a Pearson chi-square test or Fisher exact test of proportions. Logistic regression was performed to assess for associations between various factors and high fusion rate (Grade 4 or 4-) and low fusion rate 12 or more months after surgery. Analysis was performed using commercially available statistical software (SPSS 22.0, IBM).

\section{Results \\ Fusion Rate}

The average CT fusion grade for this cohort of patients was 4 , indicating solid fusion in a majority of our cohort (Fig. 2). A solid fusion mass (Grade 4- or 4) was found after 33 of 37 procedures $(89.2 \%)$ at 12 or more months after surgery. There were no cases of significant graft resorption. In 3 of 34 cases (8.8\%) reoperation was required for clinically significant pseudarthrosis. One of 37 procedures 


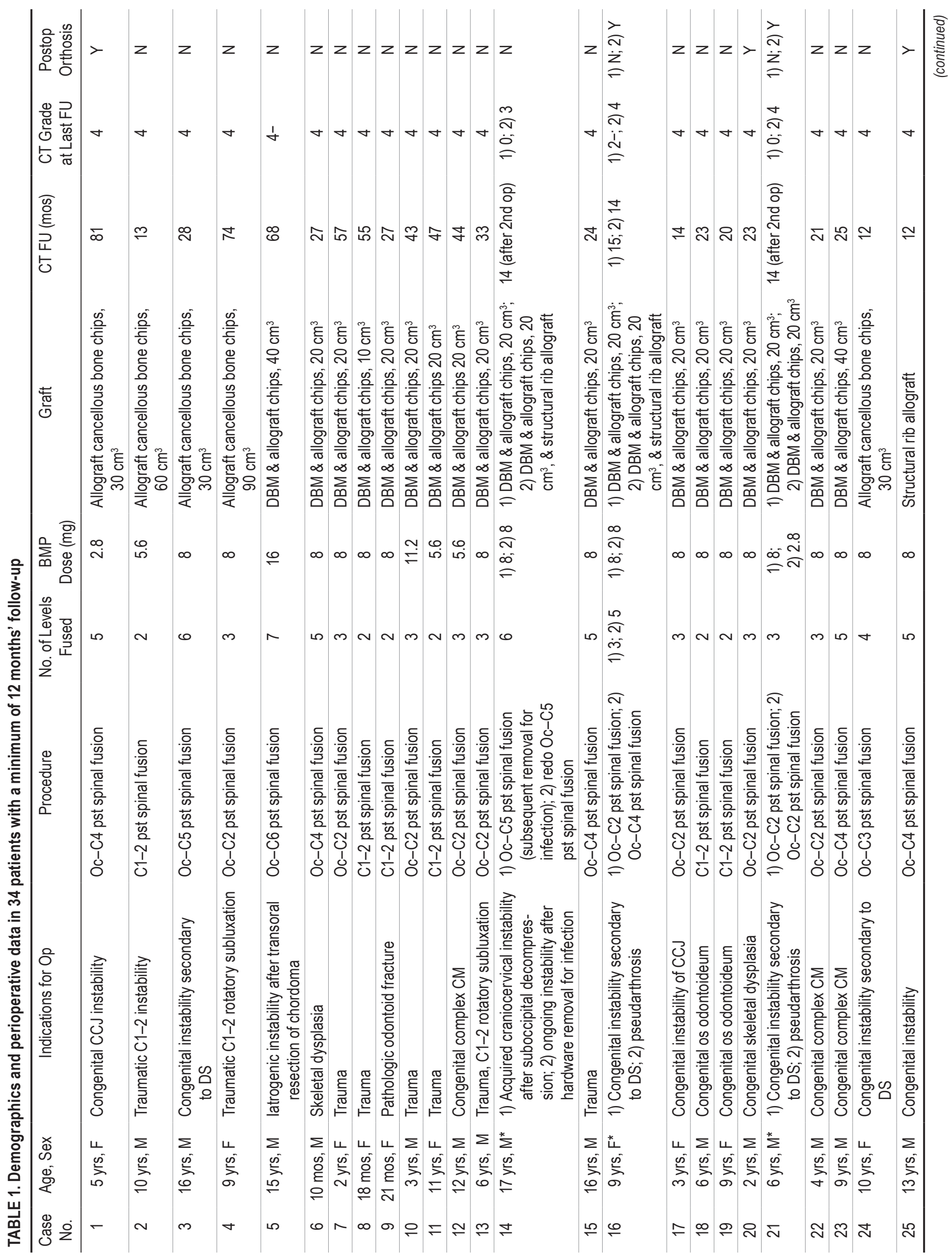




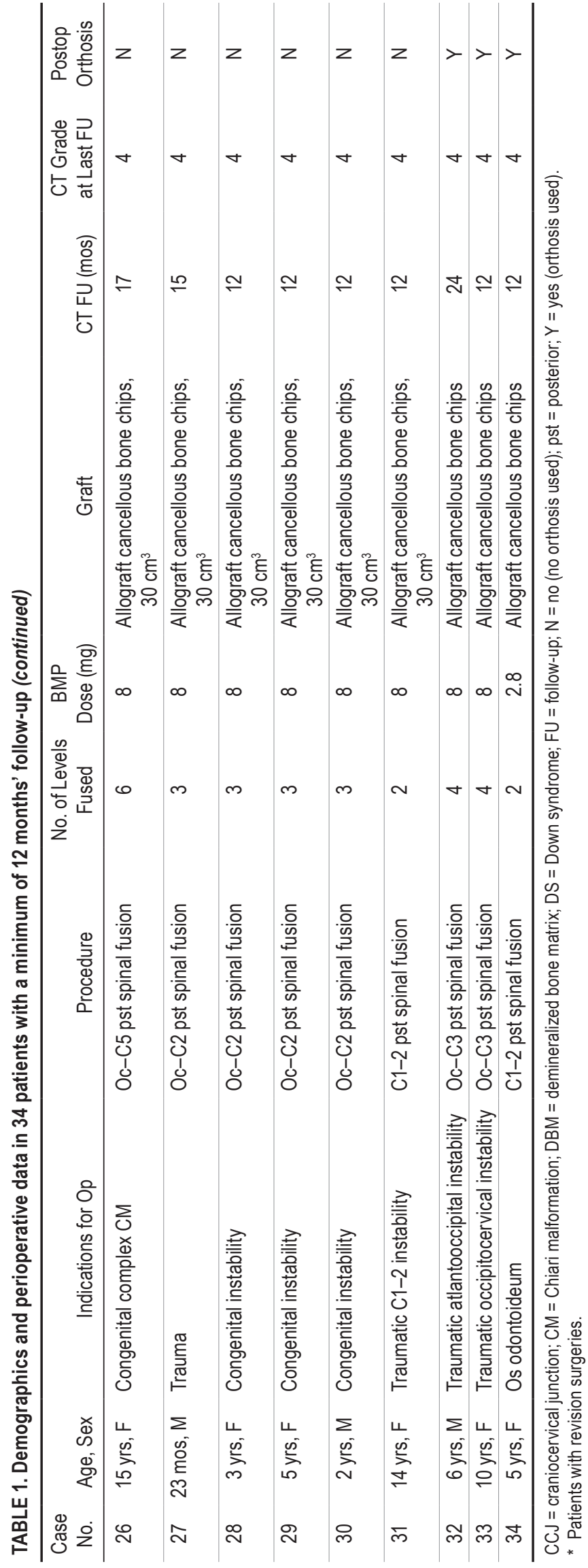

TABLE 2. Numerical CT-based grading scale for fusion assessment

\begin{tabular}{cl}
\hline Grade & \multicolumn{1}{c}{ Description } \\
\hline 0 & $\begin{array}{l}\text { Clinically significant pseudarthrosis necessitating immediate } \\
\text { revision op }\end{array}$ \\
\hline 1 & Complete graft resorption \\
\hline $2-$ & Unilat bridging bone $w /$ focal areas of graft resorption \\
\hline 2 & Unilat bridging bone \\
\hline $3-$ & Bilat bridging bone $w /$ focal areas graft resorption \\
\hline 3 & Bilat bridging bone \\
\hline $4-$ & $\begin{array}{l}\text { Evidence of bony fusion } w / \text { focal areas of incomplete incorpo- } \\
\text { ration into fusion mass }\end{array}$ \\
\hline 4 & Solid bony fusion mass \\
\hline
\end{tabular}

(2.7\%) resulted in a CT fusion grade of 3 at 14 months after surgery; however, the patient is doing well, with no clinical or radiographic signs of instability. No revision surgery is indicated.

There were no other adverse effects related to BMP use, such as bony overgrowth causing stenosis or postoperative seroma formation requiring reoperation.

\section{Factors Associated With Fusion Rate}

Univariate analysis showed that BMP dose, number of levels, and age had no association with a lower fusion rate (Table 3). Furthermore, multivariate logistic regression
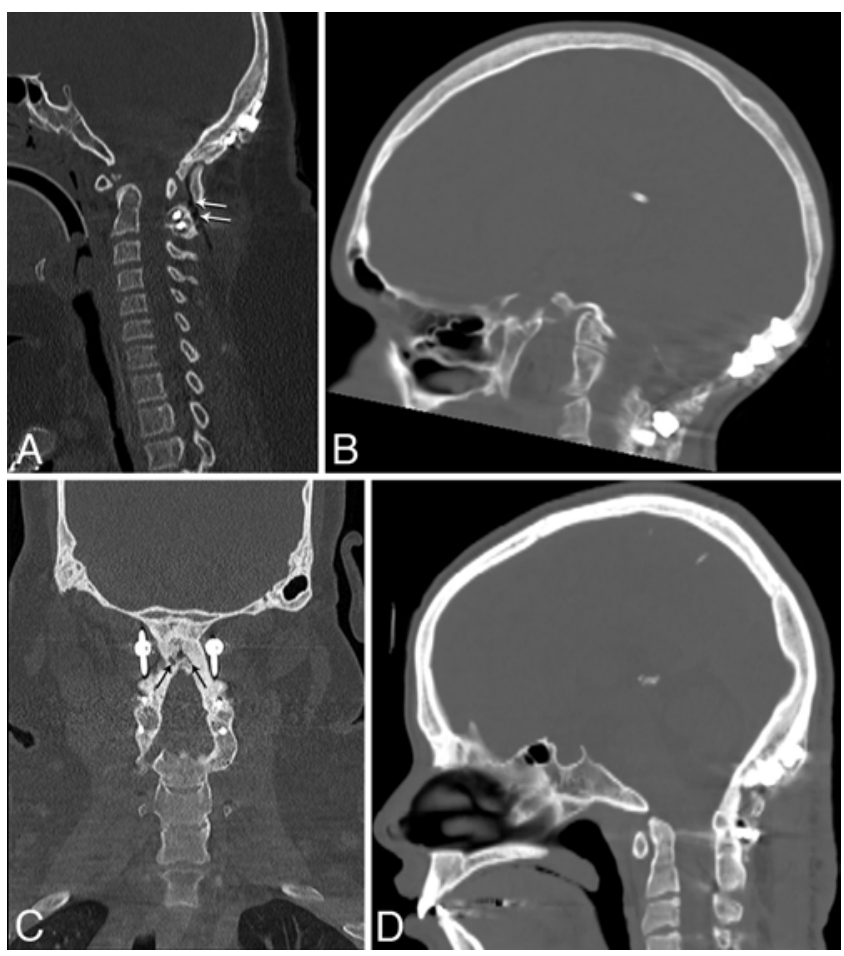

FIG. 1. Representative axial CT scans illustrating the grading scale for fusion assessment. A: Grade 2-, unilateral bridging bone with focal areas of graft resorption (arrows) (Case 16). B: Grade 3, bilateral bridging bone (Case 14). C: Grade 4-, bony fusion with focal areas of incomplete incorporation (arrows) (Case 5). D: Grade 4, solid bony fusion mass (Case 3 ). 


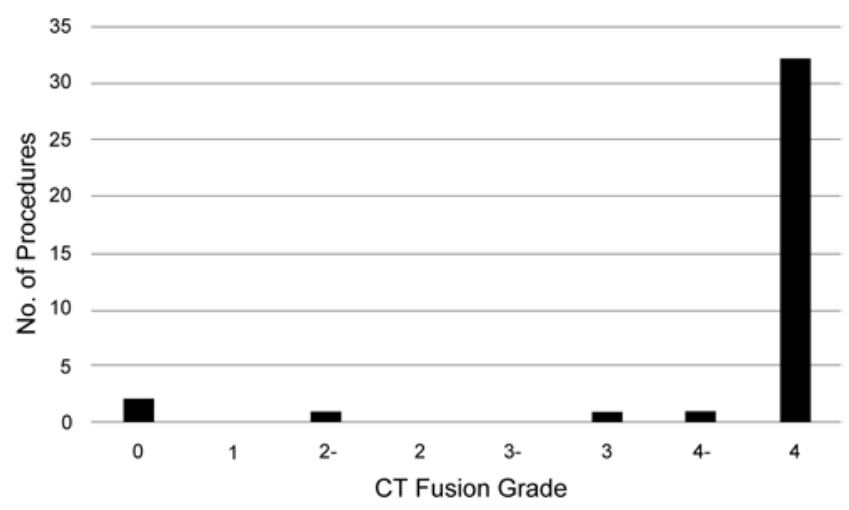

FIG. 2. Bar graph showing fusion grades at 12 or more months after surgery.

analysis demonstrated no association between high fusion grade (4- or 4) versus low fusion grade (3 or below) in relation to age, sex, BMP dose, type of graft material, use of postoperative orthosis, and the number of vertebral levels fused (Table 4).

\section{Discussion}

The osteoinductive role of rhBMP-2 is multifaceted, as it acts as a chemotactic agent, a growth factor, and a differentiation factor. ${ }^{20}$ The FDA has approved rhBMP-2 as the first complete bone graft substitute for anterior interbody fusions of the adult lumbar spine. ${ }^{21}$ In clinical trials, authors have demonstrated the usefulness of rhBMP-2 for single-level anterior interbody fusion of the adult lumbar spine, resulting in greater radiographic fusion rates, improved Oswestry Disability Index scores, and a higher rate of overall clinical success $(91.2 \%)$ compared with traditional bone grafting techniques. ${ }^{2,4}$

Although the FDA has only approved the use of rhBMP-2-soaked absorbable collagen sponges for use in adult anterior interbody lumbar fusion, "off-label" applications have been reported. ${ }^{6,14}$ We have previously reported the early results with respect to safety and efficacy of rhBMP-2 use for posterior spinal fusions in the pediatric population (mean follow-up of 11 months). ${ }^{9}$

\section{Advantages}

Biomechanically, the rhBMP-2-generated fusion mass is superior at 3 months, as compared with that generated by autograft. ${ }^{17,18}$ Findings have shown the fusion mass to be more mature, with more advanced remodeling and marrow formation, than that generated by autograft alone.
TABLE 4. Multivariate analysis for fusion rate and the effect of age, sex, dosage of BMP, number of levels fused, type of graft material, or use of postoperative orthosis*

\begin{tabular}{|c|c|c|c|}
\hline \multirow[b]{2}{*}{ Variable } & \multicolumn{3}{|c|}{ Multivariate } \\
\hline & $\mathrm{p}$ Value & OR & $95 \% \mathrm{Cl}$ \\
\hline Age & 0.9987 & 0.00 & NA \\
\hline \multicolumn{4}{|l|}{$<8 \mathrm{yrs}$} \\
\hline \multicolumn{4}{|l|}{$\geq 8 \mathrm{yrs}$} \\
\hline Sex & 0.9988 & 2261.79 & NA \\
\hline \multicolumn{4}{|l|}{ Male } \\
\hline \multicolumn{4}{|l|}{ Female } \\
\hline Dosage of BMP & 0.9994 & 0.00 & NA \\
\hline \multicolumn{4}{|l|}{$<8 \mathrm{mg}$} \\
\hline \multicolumn{4}{|l|}{$\geq 8 \mathrm{mg}$} \\
\hline No. of levels fused & 0.9989 & 0.00 & NA \\
\hline \multicolumn{4}{|l|}{2} \\
\hline \multicolumn{4}{|l|}{$>2$} \\
\hline Graft & 0.9986 & 0.00 & NA \\
\hline \multicolumn{4}{|c|}{ DBM \& allograft chips } \\
\hline \multicolumn{4}{|c|}{ Other allograft } \\
\hline Postop orthosis & 0.9988 & 0.00 & NA \\
\hline \multicolumn{4}{|l|}{ Yes } \\
\hline \multicolumn{4}{|l|}{ No } \\
\hline \multicolumn{4}{|c|}{$\begin{array}{l}\text { NA = not applicable. } \\
{ }^{*} \text { The odds ratio and } 95 \% \text { confidence interval could not be calculated for every } \\
\text { variable because the difference between the fusion and nonfusion groups was } \\
\text { negligible. None of the variables in the multivariate logistic regression model } \\
\text { had a significant association with low fusion grade. }\end{array}$} \\
\hline
\end{tabular}

In our previous study, ${ }^{9}$ we did not expect to find large mature fusion masses (Grade 4) in our posterior spine fusions in the early postoperative period, but this occurred in 2 patients $(10.5 \%)$. Bone healing and remodeling may take up to 12 to 24 months. ${ }^{8}$ However, we did expect to see advanced bone healing, at least in the form of bilateral stable bridging bone (Grades 3-, 3, 4-, and 4) across the segment of spine where we laid down rhBMP-2 and bone graft/ graft extenders, and this occurred in 16 patients (84.2\%).

Another advantage of rhBMP-2 is its potential role in promoting fusion in very young children. Although our study only included 7 patients younger than 3 years of age, we found these patients to have a very limited amount of bone available for autograft harvest without adding morbidity. In a prospective randomized study analyzing rhBMP-2 use in anterior lumbar interbody fusion surger-

TABLE 3. Univariate analysis for fusion rate compared with age, BMP dose, and number of levels, respectively*

\begin{tabular}{lccccc}
\hline \multicolumn{1}{c}{ Variable } & Mean for Fused Cohort & Mean for Unfused Cohort & Mean Difference & $95 \% \mathrm{Cl}$ & $\mathrm{p}$ Value \\
\hline Age $(\mathrm{mos})$ & 88.73 & 141 & -52.27 & -114.48 to 9.94 & 0.0969 \\
\hline Dosage of BMP & 3.52 & 4.5 & -0.98 & -2.71 to 2.007 & \\
\hline \multicolumn{1}{c}{$\mathrm{mg}$ vs $\geq 8 \mathrm{mg}$} & & & & & 0.7640 \\
\hline Number of levels fused & 7.648 & 8 & -0.352 & -2.5 to 0.53 & 0.1946 \\
\hline
\end{tabular}

* The odds ratios could not be calculated because the difference between the fusion and nonfusion groups was negligible (not statistically significant). None of the independent variables had a significant association with low fusion rate.

$\dagger$ Fused minus unfused. 
ies for adult patients, ${ }^{4}$ the authors reported adverse events with iliac crest harvesting in 8 patients $(5.9 \%)$, with onethird of this group (32\%) reporting discomfort at the graft site 12 months after surgery. By using BMP and allograft, the authors hoped to avoid complications and morbidity associated with autograft harvest; this has been our surgical philosophy as well.

\section{Long-Term Fusion Rates}

The long-term ( $\geq 12$ months) efficacy of BMP in our series, focusing on fusion rate, was surprisingly low (89.2\%) when compared with previously reported fusion rates in the literature. ${ }^{12}$ Fusion rates following placement of rigid internal instrumentation for occipitocervical and atlantoaxial instability reportedly approach $100 \%$. Surgeons increasingly select graft materials other than structural autograft. In a recent 2013 presentation at the Annual Meeting of the American Society of Pediatric Neurosurgeons (ASPN), Hankinson et al. (Hankinson TC, Anderson RCE, Brockmeyer DL, Torok M, Libby AM, Pediatric Craniocervical Society: Comparison of Fusion Rates Following Occipitocervical and Atlantoaxial Instrumented Arthrodesis Using Administrative Datasets. Paper presented at the 2013 Annual Meeting of the American Society of Pediatric Neurosurgeons, Kauai, Hawaii, USA, February 14, 2013) presented data from insurance claims databases (MarketScan and PharMetrics) demonstrating that rates of fusion failure are higher than in previous reports. The selection of allograft versus structural autograft did not affect failure rates.

\section{Factors Associated With Fusion Rates}

Factors such as patient age, sex, BMP dose, type of graft material, number of levels fused, and use of postoperative orthosis did not have any statistically significant association with lower fusion rate on multiple regression modeling.

It is very likely that the number of levels fused is associated with fusion status. Our series included 8 patients who underwent fusion procedures involving $\mathrm{C} 1-2$ only; all of these patients went on to attain Grade 4 (solid) fusion. This is consistent with the spine literature-single-level fusion has a higher rate of arthrodesis than multilevel fusion. However, our study is underpowered and unable to detect a statistical difference in number of levels fused as it relates to fusion status, and this is a limitation.

A cervical collar (e.g., Miami J or Aspen collar) is not expected to confer additional biomechanical stability at or immobilization of the craniocervical junction in the postoperative period to aid bony healing. Therefore, we do not expect an increase in fusion rate with the postoperative use of cervical collars. We used the cervical collar as a means of keeping children out of strenuous physical activities and as a reminder for our patients and others around them to be more cautious during the period of convalescence. More importantly, postoperative orthoses were not routinely used in our series. The number of patients $(n=8)$ with postoperative external orthoses entered into our logistic regression analysis was very small, and the study was underpowered to detect a statistically significant difference in the use of external orthoses as it relates to fusion status.

To define any risk factors through meaningful statistics that may be associated with the occurrence of fusion or nonfusion based on CT scans performed at least 12 months after surgery, larger cohorts would need to be studied in a multi-institutional setting.

Our data presented in this study, as well as in the aforementioned study based on large administrative data sets, suggest that the fusion rate is unexpectedly lower than previously reported in the literature for the pediatric age group. Perhaps other patient-related or procedure-related factors, such as a history of Down syndrome or spinal instrumentation density, not analyzed in our present study, have more important implications on fusion rate.

It is also possible that previous studies in the literature have underreported failures of occipitocervical fusions, as most of these prior reports determined fusion rates with plain radiographs only. CT is the gold standard in determining fusion status, especially at the craniocervical junction where anatomy is not delineated with radiographs alone. Although dynamic radiographs expose the patient to less radiation than $\mathrm{CT}$, they have several drawbacks, including low interobserver reliability of measurements, 2D nature, overestimation of solid fusion, and the lack of normative data to establish the degree of allowable motion across a fused segment. ${ }^{19}$ Many institutions have now implemented tailored lower-radiation-dose CT protocols for children. We favor our use of CT rather than dynamic radiographs to determine fusion as the reason for our low fusion rate, given the concordance of our results with those of Hankinson et al. (Hankinson TC, Anderson RCE, Brockmeyer DL, Torok M, Libby AM, Pediatric Craniocervical Society: Comparison of Fusion Rates Following Occipitocervical and Atlantoaxial Instrumented Arthrodesis Using Administrative Datasets. Paper presented at the 2013 Annual Meeting of The American Society of Pediatric Neurosurgeons, Kauai, Hawaii, USA, February 14, 2013).

\section{Limitations}

The current study was based on a retrospective chart review of surgical cases of 2 surgeons at 2 institutions. Thus, it was subject to an inherent selection bias. Moreover, there was no control group to compare outcomes with our rhBMP-2 cohort except historical data. Given the relatively few patients with pseudarthrosis (4 of 37 surgeries) and 6 clinical factors analyzed for statistical significance, our study was underpowered, and it was difficult for a logistic regression model to accurately deduce factors that may be associated with failure of fusion.

A significant number of patients were excluded from our study (49/83 or $59 \%)$. Sixty patients underwent surgery at $\mathrm{TCH}$ and 23 patients underwent surgery at $\mathrm{RCH}$ for a total cohort of 83 . Of the 60 patients from TCH, 31 were included in our study; 21 were excluded because they either did not have CT imaging at 12 or more months after surgery (18 patients) or due to death (3 patients). CT imaging was not performed because of patient or parent refusal secondary to cost or concerns about radiation. The 3 deaths in the TCH cohort were due to respiratory failure after tracheostomy dislodgement remote from surgery, propofol infusion syndrome, and a massive pulmonary embolism after surgery. Eight patients from TCH were 
lost to follow-up. Of the 23 patients from $\mathrm{RCH}, 3$ were included in our study; 20 were excluded because they did not have CT imaging at 12 or more months after surgery (18 patients) or they died in follow-up (2 patients, with death in both cases being associated with traumatic atlantooccipital dislocation and withdrawal of care).

\section{Conclusions}

Recombinant human BMP-2 has proven to be a valuable adjunct for achieving bone fusion in spine surgery. However, prior to our studies, little had been published regarding the use of rhBMP-2 in the pediatric population. Our previously published early postoperative results showed safety and efficacy for routine use of rhBMP-2 similar to what has been demonstrated regarding its use in the adult population. Previous studies of pediatric occipitocervical and atlantoaxial constructs have reported fusion rates between $98 \%$ and $100 \%$. While a high rate of bony healing is evident, the long-term fusion rates are disappointingly low (89.2\%). Factors such as patient age, sex, BMP dose, type of graft material, number of levels fused, and use of postoperative orthosis were found not to have any association with CT-proven fusion at 12 or more months after surgery. Therefore, although rhBMP-2 is a reasonable alternative to harvested rib or hip autograft, it should be used judiciously in pediatric occipitocervical and atlantoaxial fusion procedures, given its added costs and risks without a dramatically higher rate of fusion.

\section{References}

1. Blanco JS, Sears CJ: Allograft bone use during instrumentation and fusion in the treatment of adolescent idiopathic scoliosis. Spine (Phila Pa 1976) 22:1338-1342, 1997

2. Boden SD, Zdeblick TA, Sandhu HS, Heim SE: The use of rhBMP-2 in interbody fusion cages. Definitive evidence of osteoinduction in humans: a preliminary report. Spine (Phila Pa 1976) 25:376-381, 2000

3. Bridwell KH, Lenke LG, McEnery KW, Baldus C, Blanke $\mathrm{K}$ : Anterior fresh frozen structural allografts in the thoracic and lumbar spine. Do they work if combined with posterior fusion and instrumentation in adult patients with kyphosis or anterior column defects? Spine (Phila Pa 1976) 20:14101418,1995

4. Burkus JK, Gornet MF, Dickman CA, Zdeblick TA: Anterior lumbar interbody fusion using rhBMP-2 with tapered interbody cages. J Spinal Disord Tech 15:337-349, 2002

5. Burkus JK, Gornet MF, Schuler TC, Kleeman TJ, Zdeblick TA: Six-year outcomes of anterior lumbar interbody arthrodesis with use of interbody fusion cages and recombinant human bone morphogenetic protein-2. J Bone Joint Surg Am 91:1181-1189, 2009

6. Carlisle E, Fischgrund JS: Bone morphogenetic proteins for spinal fusion. Spine J 5 (6 Suppl):240S-249S, 2005

7. Couture D, Avery N, Brockmeyer DL: Occipitocervical instrumentation in the pediatric population using a custom loop construct: initial results and long-term follow-up experience. J Neurosurg Pediatr 5:285-291, 2010

8. Czitrom AA: Biology of bone grafting and principles of bone banking, in Weinstein SL (ed): The Pediatric Spine: Principles and Practice, ed 1. New York: Raven Press, 1994, pp $1285-1298$
9. Fahim DK, Whitehead WE, Curry DJ, Dauser RC, Luerssen TG, Jea A: Routine use of recombinant human bone morphogenetic protein-2 in posterior fusions of the pediatric spine: safety profile and efficacy in the early postoperative period. Neurosurgery 67:1195-1204, 2010

10. Glassman SD, Dimar JR, Carreon LY, Campbell MJ, Puno RM, Johnson JR: Initial fusion rates with recombinant human bone morphogenetic protein-2/compression resistant matrix and a hydroxyapatite and tricalcium phosphate/collagen carrier in posterolateral spinal fusion. Spine (Phila Pa 1976) 30:1694-1698, 2005

11. Hankinson TC, Avellino AM, Harter D, Jea A, Lew S, Pincus $\mathrm{D}$, et al: Equivalence of fusion rates after rigid internal fixation of the occiput to $\mathrm{C}-2$ with or without C-1 instrumentation. J Neurosurg Pediatr 5:380-384, 2010

12. Hood B, Hamilton DK, Smith JS, Dididze M, Shaffrey C, Levi AD: The use of allograft and recombinant human bone morphogenetic protein for instrumented atlantoaxial fusions. World Neurosurg 82:1369-1373, 2014

13. Hwang SW, Gressot LV, Rangel-Castilla L, Whitehead WE, Curry DJ, Bollo RJ, et al: Outcomes of instrumented fusion in the pediatric cervical spine. J Neurosurg Spine 17:397409, 2012

14. Lu DC, Sun PP: Bone morphogenetic protein for salvage fusion in an infant with Down syndrome and craniovertebral instability. Case report. J Neurosurg 106 (6 Suppl):480-483, 2007

15. Mazur MD, Sivakumar W, Riva-Cambrin J, Jones J, Brockmeyer DL: Avoiding early complications and reoperation during occipitocervical fusion in pediatric patients. J Neurosurg Pediatr 14:465-475, 2014

16. Menezes AH: Craniocervical fusions in children. J Neurosurg Pediatr 9:573-585, 2012

17. Sandhu HS, Kanim LE, Kabo JM, Toth JM, Zeegan EN, Liu D, et al: Evaluation of rhBMP-2 with an OPLA carrier in a canine posterolateral (transverse process) spinal fusion model. Spine (Phila Pa 1976) 20:2669-2682, 1995

18. Schimandle JH, Boden SD, Hutton WC: Experimental spinal fusion with recombinant human bone morphogenetic protein-2. Spine (Phila Pa 1976) 20:1326-1337, 1995

19. Selby MD, Clark SR, Hall DJ, Freeman BJ: Radiologic assessment of spinal fusion. J Am Acad Orthop Surg 20:694703,2012

20. Subach BR, Haid RW, Rodts GE, Kaiser MG: Bone morphogenetic protein in spinal fusion: overview and clinical update. Neurosurg Focus 10(4):E3, 2001

21. US Food and Drug Administration: Summary of safety and effectiveness data. (http://www.accessdata.fda.gov/ cdrh_docs/pdf/P000058b.pdf) [accessed March 18, 2015]

\section{Author Contributions}

Conception and design: Jea, Hadley, Ryan. Acquisition of data: Jea, Hadley, Monaco, Sen, Brayton, Briceño, Tran, Ryan, Fulkerson. Analysis and interpretation of data: Jea, Sayama, Hadley, Monaco, Sen, Brayton, Briceño, Tran, Ryan, Fulkerson. Drafting the article: Jea, Sayama. Critically revising the article: all authors. Reviewed submitted version of manuscript: all authors. Approved the final version of the manuscript on behalf of all authors: Jea. Administrative/technical/material support: Luerssen. Study supervision: Luerssen.

\section{Correspondence}

Andrew Jea, Division of Pediatric Neurosurgery, Department of Neurosurgery, Texas Children's Hospital, Baylor College of Medicine, 6621 Fannin St., CCC 1230.01, 12th Fl., Houston, TX 77030. email: ahjea@texaschildrens.org. 